\title{
Factors affecting supervisors' enactment of interpersonal fairness: The interactive relationship between their managers' informational fairness and supervisors' sense of power
}

\author{
Joel Brockner ${ }^{1}$ | David De Cremer ${ }^{2,3}$ | Marius van Dijke ${ }^{4,5}$ (ㅇ | \\ Leander De Schutter $^{5}$ | Brian Holtz ${ }^{6}$ (1) | Alain Van Hiel
}

${ }^{1}$ Columbia Business School, Columbia University, New York City, New York, U.S.A.

${ }^{2}$ Department of Management and

Organisation, National University of Singapore, Singapore

${ }^{3}$ Cambridge Judge Business School, University of Cambridge, Cambridge, UK

${ }^{4}$ Nottingham Business School, Nottingham Trent University, Nottingham, UK

${ }^{5}$ Rotterdam School of Management, Erasmus University, Rotterdam, The Netherlands

${ }^{6}$ Fox School of Business, Temple University, Philadelphia, Pennsylvania, U.S.A.

${ }^{7}$ Department of Psychology, Ghent University, Ghent, Belgium

Correspondence

David De Cremer, Department of Management and Organisation, NUS Business School, 15 Kent Ridge Drive, National University of Singapore, Singapore 119245.

Email: bizddc@nus.edu.sg

\begin{abstract}
Summary
Managerial trickle-down effects refer to the tendency for supervisors to treat their subordinates in ways analogous to how they have been treated by their own bosses. Although trickle-down effects are widely documented, including in the justice literature, less is known about the conditions under which they are more versus less likely to emerge. Across two studies, we examined how supervisors' tendencies to exhibit interpersonal fairness are interactively determined by the informational fairness they receive from managers above them and supervisors' sense of power. Study 1 was a multisource survey conducted in organizational settings. Study 2 was an experiment in which we manipulated the informational fairness that supervisors received from managers and supervisors' sense of power. The results of both studies showed that the positive relationship between the informational fairness received from managers and supervisors' enactment of interpersonal fairness was stronger among supervisors who had a lower sense of power. This interactive effect did not emerge on supervisors' enactment of other forms of fairness (distributive, procedural, and informational), consistent with prior theory and research showing that interpersonal fairness allows for greater discretion than other forms of fairness. Theoretical and practical implications are discussed as are limitations and suggestions for future research.
\end{abstract}

\section{KEYWORDS}

interpersonal fairness enactment, organizational justice, sense of power

\section{1 | INTRODUCTION}

Organizational scholars' recent interest in managers' enactment of fairness, that is, the study of managers' tendencies to behave more or less fairly towards their direct reports, has its roots in the decades of prior empirical work showing that the fairness managers exhibit to their direct reports is consequential (Adams, 1965; Bies, 1987; Lind \& Tyler, 1988; Thibaut \& Walker, 1975). In their historical review of the organizational justice literature, Colquitt, Greenberg, and ZapataPhelan (2005) reported that in many different organizational settings, a wide variety of employee beliefs (e.g., organizational commitment) and behaviors (e.g., job performance) have systematically been affected by various forms of managerial fairness (i.e., distributive, procedural, informational, and interpersonal). Overwhelmingly, employees respond more positively when they have been treated more fairly by their managers.

There has been a paradigmatic shift since the Colquitt et al. (2005) review. Increasingly, scholars are examining organizational justice as a dependent variable (Brockner, Wiesenfeld, Siegel, Bobocel, \& Liu, 2015). One particularly fruitful approach has investigated when and why managers treat their direct reports more versus less fairly. Conceptual papers include those of Molinsky and Margolis (2005), 
who offered a thoughtful analysis of when managers deliver bad news with interpersonal sensitivity, and Scott, Colquitt, and Paddock (2009), who provided a comprehensive framework of the motives that lead managers to behave more or less fairly; see also Ambrose and Schminke (2009).

The growing empirical literature on managers' fairness towards their direct reports has examined an array of factors such as those pertaining to the managers enacting the fairness and to the direct reports on the receiving end. For instance, Scott, Garza, Conlon, and Kim (2014) showed that managers' motives ("hot vs. cold") were differentially predictive of various forms of justice. Brebels, De Cremer, van Dijke, and Van Hiel (2011) found that managers with stronger moral identity were more likely to adhere to several principles of procedural fairness (accuracy and voice). Other studies examining factors associated with the recipients of the fairness have shown that employees' trustworthiness influences managers' tendencies to be informationally, interpersonally, and procedurally fair (Zapata, Olsen, \& Martins, 2013; Zhao, Chen, \& Brockner, 2015).

In addition to the influence on managerial fairness of factors associated with managers and their direct reports, encounters between the two parties take place in a broader context. One particularly salient contextual factor in organizational life is hierarchy: Managers responsible for enacting decisions typically have bosses as well. That is, managers are at once agents as well as recipients of decisions (Bryant \& Stensaker, 2011; Floyd \& Wooldridge, 1992; Shi, Markoczy, \& Dess, 2009). Thus, another important determinant of managerial fairness is how they were treated by their own bosses.

Support for this assertion comes from theory and research on trickle-down effects, which has gained popularity in organizational behavior in general and in the organizational justice literature more specifically (e.g., Ambrose, Schminke, \& Mayer, 2013; Wo, Ambrose, \& Schminke, 2015). The essence of a trickle-down effect is that supervisors' perceptions of their managers' actions influence how those same supervisors act towards others at lower levels. In line with this approach, research on justice trickle-down effects suggests that the fairness with which those in positions of authority are treated by their managers may influence the fairness that they exhibit towards their direct reports (Ambrose et al., 2013; Folger, Ganegoda, Rice, Taylor, \& Wo, 2013; Masterson, 2001; Mawritz, Mayer, Hoobler, Wayne, \& Marinova, 2012; Tepper \& Taylor, 2003; Wayne, Liden, Graf, \& Ferris, 1997; Wo et al., 2015).

More recently, however, it has been suggested that supervisors do not always "do unto others as has been done unto them" to the same degree (e.g., van Houwelingen, van Dijke, \& De Cremer, 2017). In the present research, we seek to provide deeper insight into the question of when supervisors are more versus less likely to exhibit fairness to their employees as a function of how fairly they were treated by their own bosses. Delineating when justice trickle-down effects are more versus less likely is theoretically and practically important. For example, at a theoretical level, we can better understand why certain justice trickle-down effects occur to the extent we can demonstrate when they are more versus less likely to occur. Moreover, at a practical level, given the pervasive effects that managers' fairness can have on employees' work attitudes and behaviors, organizations have much to gain by understanding when managers' fairness at one level is more versus less likely to ripple through the ranks of supervisors at lower levels of the organization. (From this point forward, in discussing trickle-down effects, we refer to those at higher levels of authority as "managers" and those at lower levels as "supervisors.")

More specifically, we examine the impact of managers' informational fairness (Colquitt, 2001), that is, how well managers explain their or the organizations' decisions to supervisors below them, on supervisors' enactment of interpersonal fairness to their own direct reports. Given the high degree of uncertainty in many workplace environments (Bradley, Shepherd, \& Wiklund, 2011), a particularly useful type of behavior for sense-making purposes is managers' informational fairness, that is, the explanations that managers provide about why decisions are made. Managers are well situated to be sources of informational fairness in several respects. First, they usually have a broader base of knowledge and therefore a better understanding of why decisions are made, relative to supervisors further down the hierarchy (Katz \& Kahn, 1978). Furthermore, being at higher levels gives managers legitimate authority to explain organizational decisions (Katz \& Kahn, 1978; Van der Toorn, Tyler, \& Jost, 2011).

Yet another reason to examine the trickle-down effect of managers' informational fairness is that it is a form of fairness of relatively high frequency. Although other forms of managerial fairness such as distributive fairness and procedural fairness are exhibited primarily when resource allocation decisions are made (Mikula, Petri, \& Tanzer, 1990), informational fairness is enacted not only in resource allocation contexts but also in the course of more everyday interactions between managers and their direct reports, such as when managers explain the reasons for a new strategic initiative or why changes in policy or procedure are being planned or implemented.

Although we expect managers' informational fairness to be positively related to supervisors' interpersonal fairness, of greater importance, we seek to evaluate when such a justice trickle-down effect may be more versus less likely to occur. One plausible determinant of variability in trickle-down effects is the sense of power felt by supervisors, which has been defined as the perception of one's ability to influence others (Anderson, John, \& Keltner, 2012). We examined how supervisors' sense of power could influence the magnitude of the trickle-down effect, for two reasons. First, supervisors' sense of power determines how receptive they are to external versus internal sources of information as guides for their own behavior (Galinsky, Rucker, \& Magee, 2015). As we explain further below, this assertion provides a theoretical basis to predict that the trickle-down effect will be stronger among supervisors with a lower sense of power. Second, employees' sense of power is fundamentally related to the hierarchical nature of organizational life, which in turn sets the stage for the study of managerial trickle-down effects. Indeed, where employees reside in the hierarchy is one (but by no means the only) factor that affects their sense of power. 


\subsection{Specifying the nature of the moderating effect of supervisors' sense of power}

Supervisors who have a lower sense of power are more externally focused and therefore are more susceptible to being influenced by environmental cues (Galinsky, Magee, Gruenfeld, Whitson, \& Liljenquist, 2008). Accordingly, we would expect that the positive relationship between managers' informational fairness and supervisors' interpersonal fairness is more likely to be shown by supervisors with a lower sense of power. In contrast, supervisors with a stronger sense of power are less likely to be influenced by external cues and instead may be more likely to act on internal drivers of behavior (Chen, LeeChai, \& Bargh, 2001; DeCelles, DeRue, Margolis, \& Ceranic, 2012), such as their own values, attitudes, and preferences.

The findings of Pitesa and Thau (2013) are consistent with the notion that those with a lower sense of power are more influenced by external cues for appropriate behavior. In two of their studies, participants experiencing varying degrees of power were placed in an ethical dilemma in which they were given information about how peers facing the same situation had behaved. Those with a lower sense of power were more likely to behave the way their peers did, relative to their counterparts who experienced a higher sense of power. Pitesa and Thau thus found that in a nonhierarchical setting, people's sense of power dictated their reliance on external cues to guide their own behavior. Although Pitesa and Thau looked at how cues coming from peers affected participants' tendency to behave ethically, we examine how cues coming from parties higher up in the hierarchy affect participants' tendencies to behave fairly. We expect the positive relationship between managers' informational fairness and supervisors' interpersonal fairness towards their direct reports to be stronger among supervisors with a lower sense of power.

Another noteworthy purpose of the present research is to evaluate whether supervisors' sense of power will moderate the effect of managers' informational fairness on supervisors' enactment of interpersonal fairness in particular, rather than on supervisors' enactment of other forms of fairness (distributive, procedural, and informational). If this prediction is supported, it would serve the theoretically important purpose of delineating a way in which interpersonal fairness meaningfully differs from the other forms of fairness. In Study 1 , supervisors rated the informational fairness that their managers showed to them and were then rated by their direct reports on how much they (the supervisors) exhibited various forms of fairness: interpersonal, distributive, procedural, and informational.

\section{2 | Distinguishing interpersonal fairness from other forms of fairness}

As Scott et al. (2009) theorized and as Scott et al. (2014) empirically demonstrated, interpersonal fairness allows for greater discretion in how to behave than do the other forms of fairness. Discretion refers to the amount of latitude that people have when formulating or implementing their actions. In their typical role as implementers of decisions, supervisors have relatively little input into the distributive, procedural, and informational fairness of decisions reserved more for those at higher levels of management. Interpersonal fairness, however, is different. It refers to the way in which supervisors carry out their roles and in particular the extent to which they treat their subordinates with dignity and respect when implementing organizational decisions. Supervisors may have relatively little influence over other forms of fairness, but they have considerable discretion to behave with more versus less interpersonal fairness (Zapata, Carton, \& Liu, 2016).

The prediction that supervisors' sense of power is likely to moderate the relationship between managers' informational fairness and supervisors' interpersonal fairness in particular is theoretically grounded in the work of Mischel (1973) and Judge and Zapata (2015), who showed that the extent to which factors residing within persons influence their work behaviors depends on situational strength. Strong situations are those in which people receive clear cues on how to behave, thereby minimizing the influence of factors residing within persons (such as their sense of power). Weak situations are more ambiguous, thereby allowing for person variables to influence beliefs and behaviors. Importantly, Mischel posited that a major determinant of situational strength is how much discretion the situation allows people to have in how to respond; strong situations allow for little discretion, whereas weak situations afford greater discretion.

Given the greater discretion associated with interpersonal fairness relative to the other forms of fairness, it stands to reason that theoretically relevant factors residing within persons (such as their sense of power) are more likely to influence their enactment of interpersonal fairness. ${ }^{1}$ If those with a weaker sense of power are more responsive to external cues for appropriate behavior (e.g., how others have behaved), then the moderating effect of sense of power on the relationship between managers' informational fairness and supervisors' fairness behavior should be most likely to emerge on the form of supervisor fairness allowing for the greatest discretion, that is, interpersonal fairness. In other words, we expect the trickle-down effect of managers' informational fairness on supervisors' interpersonal fairness will be more likely to emerge among supervisors with a lower sense of power.

In summary, the above reasoning leads to the central hypothesis of the present studies:

Managers' informational fairness and supervisors' sense of power will interact to influence supervisors' enactment of interpersonal fairness to their direct reports. Specifically, the tendency for supervisors to show more interpersonal fairness towards their direct reports when they received greater informational fairness from their managers will be stronger among supervisors with a lower sense of power.

${ }^{1}$ In depicting sense of power as a factor residing within people, we are not necessarily conceptualizing it to be a relatively stable individual difference variable. It can be, but it also can be a psychological state (Anderson et al., 2012). 
Having set forth our primary hypothesis, we are not suggesting that the moderating effect of supervisors' sense of power only applies to the relationship between managers' informational fairness and supervisors' interpersonal fairness. Put differently, it is possible for supervisors' sense of power to moderate the influence of other forms of managerial fairness (such as their interpersonal fairness) on supervisors' interpersonal fairness. Indeed, we test this hypothesis in a subsidiary analysis in Study 1.

\section{3 | Plan of study}

We conducted two studies. Study 1 consisted of a cross-sectional field study in which we measured supervisors' enactment of distributive, procedural, and informational fairness in addition to our focal dependent variable: supervisors' interpersonal fairness. Given prior theory and research on managerial trickle-down effects in the realm of fairness, we expect that managers' informational fairness will be positively related to supervisors' enactment of all dimensions of fairness (distributive, procedural, informational, and interpersonal). However, we posit that the person variable (supervisors' sense of power) is less likely to interact with the managers' informational fairness to influence supervisors' expression of distributive, procedural, and informational fairness because of the lesser discretion associated with these other dimensions of fairness relative to interpersonal fairness.

Study 1 consisted of a multisource survey in which employees and their supervisors from a wide variety of organizations participated. Supervisors completed a measure of their sense of power and rated their managers' informational fairness when making decisions. Independently, subordinates rated their supervisors on supervisors enactment of interpersonal fairness, along with the extent to which they exhibited distributive, procedural, and informational fairness. Although Study 1 examined the enactment of interpersonal fairness in actual organizational settings, the cross-sectional nature of Study 1 made it difficult to draw causal inferences. We redressed this shortcoming in Study 2, which consisted of an experiment in which the independent variables of managers' informational fairness and supervisors' sense of power were manipulated. If converging results emerge across different research designs with varying strengths and weaknesses, we gain confidence in the construct validity of the findings (Campbell \& Fiske, 1959; De Cremer, Van Dijke, Schminke, De Schutter, \& Stouten, 2018).

\section{2 | STUDY 1}

\section{1 | Methods}

\subsubsection{Sample and procedure}

We recruited participants through Flycatcher, a professionally managed research panel founded by Maastricht University. Flycatcher meets the ISO 26362 requirements, a quality label certifying that this panel can be used for social science research. The panel consists of 16,000 Dutch citizens who participate in a maximum of eight surveys a year. In return for their voluntary participation, panel members receive points that they can exchange for gift vouchers. Flycatcher first contacted participants who had administrative positions at their current organizations ("supervisors") and asked them to complete an online survey and identify one of their subordinates by entering the subordinate's email address. A message containing a link to another survey was then automatically sent to subordinates. We used a unique identification code to match the responses of supervisors and subordinates, which also ensured anonymity. We took several steps to ensure that the correct sources completed the surveys. For example, we emphasized throughout the process that integrity is crucial in the scientific process of survey research and stressed that it was necessary that supervisors and their matched subordinates completed the correct survey. In addition, the use of IP addresses and time stamps allowed us to verify that surveys were submitted from different IP addresses and at different times.

We asked Flycatcher to gather $\sim 100$ unique supervisorsubordinate dyads. ${ }^{2}$ To collect this number of dyads, Flycatcher first contacted 853 supervisors. In total, Flycatcher provided us with 102 unique complete dyads. Supervisors were on average 43.73 years old $(S D=10.42) ; 68.6 \%$ were male and $31.4 \%$ female. They had an average organizational tenure of 11.67 years $(S D=7.35)$, job tenure of 8.29 years $(S D=6.09)$, and worked on average of $36.55 \mathrm{~h}$ $(S D=7.36)$ per week. Subordinates of the supervisors were on average 40.93 years old $(S D=11.82$ ); $59.8 \%$ were male and $40.2 \%$ female. On average, they had worked for 10.26 years $(S D=8.47)$ in their current organization, 8.43 years $(S D=7.87)$ in their current position, and worked an average of $34.35 \mathrm{~h}(S D=8.91)$ per week.

\section{2 | Measures}

All measures pertaining to the primary purpose of the study are reported below. Supervisors rated their sense of power and the informational fairness shown to them by their managers, in that order. Subordinates of supervisors indicated the extent to which their supervisor enacted procedural, distributive, interpersonal, and informational fairness, in that order. The measures of sense of power and informational fairness were rated using a 5-point Likert scale (1, strongly disagree; 5 , strongly agree), and the remaining scales were rated using a 7-point Likert scale ( 1 = strongly disagree; 7 = strongly agree).

We measured supervisors' sense of power with the 8-item senseof-power scale (Anderson et al., 2012; Anderson \& Galinsky, 2006), tailored to the context of their organization (van Dijke, De Cremer,

${ }^{2}$ There were no established effects on which to base our sample size. Therefore, in Study 1 , we collected data from the number of respondents similar to what was done in other multisource studies in the justice literature (e.g., van Gils, Van Quaquebeke, van Knippenberg, van Dijke, \& De Cremer, 2015; Zheng, Yuan, van Dijke, De Cremer, \& Van Hiel, 2018). For Study 2, we followed Simmons, Nelson, and Simonsohn's (2013) recommendation of using at least 50 participants in every cell. 
Langendijk, \& Anderson, 2018; e.g., "In this organization, I can get people to listen to what I say").

As recommended by Bobocel and Zdaniuk (2005), we measured supervisors' perceptions of their managers' informational fairness along the dimensions of sincerity, adequacy, and legitimacy. We measured sincerity and adequacy with 2-item scales, both taken from Bies, Shapiro, and Cummings (1988). Sample items include "My boss is sincere when he/she gives reasons for his/her decisions" and "The reasons that my boss gives for his/her decisions are adequate," respectively. We measured legitimacy with two items taken from Rousseau and Tijoriwala (1999). A sample item was "The reasons that my boss gives for his/her decisions are appropriate." We combined the three measures into a 6-item scale.

We measured subordinates' perceptions of their supervisor's interpersonal fairness enactment with a 4-item scale developed by Colquitt (2001). A sample item included "My supervisor treats me in a polite manner." Finally, we also measured subordinates' perceptions of their supervisor's enactment of the other forms of fairness. Distributive fairness was measured with a 4-item scale developed by Colquitt. A sample item included "My supervisor takes the effort I have put into my work into account when he makes decisions." Procedural fairness was measured with a 7-item scale developed by Colquitt. A sample item included "My supervisor applies procedures consistently." Informational fairness was measured with a 5-item scale developed by Colquitt. A sample item included "My supervisor explains procedures thoroughly."

\section{3 | Results and discussion}

Summary statistics appear in Table 1.

Interpersonal fairness ratings were strongly skewed. Given this fact, it is likely that some of the assumptions of ordinary least squares regressions were violated, which can reduce power and inflate error variances (Wilcox \& Keselman, 2004). To correct for this, we tested our hypotheses using robust ordinary least squares (White, 1980).
We entered the main effects of supervisors' perceptions of their managers' informational fairness and supervisors' sense of power in Step 1. We entered the interaction between informational fairness and supervisors' sense of power in Step 2. We mean-centered predictors and calculated the interactions based on these scores. Table 2 shows the results on the measure of interpersonal fairness. Although both main effects were positive and significant, of greater importance, they were qualified by a significant interaction effect, $p=.017$ (see Table 2 and Figure 1).

To specify further the nature of the interaction effect, we conducted simple slopes analyses (Aiken \& West, 1991). As predicted, managers' informational fairness was positively related to supervisors' interpersonal fairness among supervisors with a lower sense of power (1 SD below the mean; $b=0.67, S E=0.22, p=.002$ ). In contrast, there was no relationship between managers' informational fairness and supervisors' interpersonal fairness among supervisors with a higher sense of power (1 SD above the mean; $b=0.12$, SE = 0.11, $p=.250$ ).

Furthermore, Tables 1 and 2 showed that as predicted, managers' informational fairness was positively related to supervisors' informational, procedural, and distributive fairness. However, in contrast to interpersonal fairness, none of these main effects was qualified by a significant interaction between managers' informational fairness and supervisors' sense of power.

\subsection{1 | Subsidiary analyses}

During the review process, it was called to our attention that other measures completed by supervisors about their managers' fairness included an aspect of interpersonal fairness. More specifically, supervisors rated their managers' tendencies to apologize (Howell, Dopko, Turowski, \& Buro, 2011), which is one way in which managers express respectful, dignified, and polite behavior, all hallmarks of interpersonal fairness (Colquitt, 2001; Greenberg, 1993). Sample measures from this 8-item scale include "To avoid feeling incompetent, my supervisor tends not to apologize" (reverse scored) and "My supervisor doesn't

TA B LE 1 Means, standard deviations, correlations, and Cronbach's alphas (Study 1)

\begin{tabular}{|c|c|c|c|c|c|c|c|c|}
\hline Variable & M & $S D$ & 1 & 2 & 3 & 4 & 5 & 6 \\
\hline \multicolumn{9}{|l|}{ Supervisor rated variables } \\
\hline 1. Managers' informational fairness & 3.82 & 0.75 & (.93) & & & & & \\
\hline \multicolumn{9}{|l|}{ Subordinate rated variables } \\
\hline 3. Interpersonal fairness & 6.00 & 1.12 & $.46^{*}$ & $.51^{*}$ & (.96) & & & \\
\hline 5. Distributive fairness & 5.60 & 1.04 & $.58^{*}$ & $.54^{*}$ & $.82^{*}$ & $.79^{*}$ & (.96) & \\
\hline 6. Procedural fairness & 5.66 & 1.06 & $.42^{*}$ & $.52^{*}$ & $.84^{*}$ & $.87^{*}$ & $.85^{*}$ & (.95) \\
\hline
\end{tabular}

Note: Cronbach's alphas are on the diagonal. The measures of manager's informational fairness and sense of power were rated using a 5-point Likert scale ( 1 = strongly disagree; 5 = strongly agree $)$, and the remaining scales were rated using a 7-point Likert scale $(1=$ strongly disagree; $7=$ strongly agree $)$.

${ }^{*} p<.001$, two-tailed tests. 


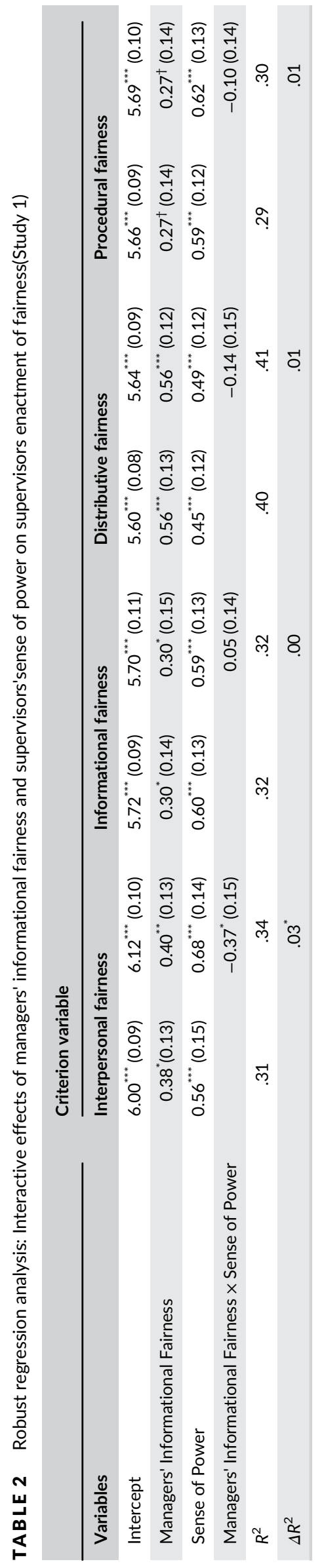

apologize very often because he/she doesn't like to admit that he/she is wrong" (reverse scored). End points on the 7-point rating scale were (1) strongly disagree and (7) strongly agree. Cronbach's alpha was .94.

Accordingly, we repeated the hierarchical regression analysis previously reported which examined the interactive effect of managers' informational fairness and supervisors' sense of power on supervisors' interpersonal fairness, with managers' tendencies to apologize substituted for informational fairness. Thus, in Step 1, we entered the main effects of managers' tendencies to apologize and supervisors' sense of power, and in Step 2, we added the interaction between managers' tendencies to apologize and supervisors' sense of power. We mean-centered predictors and calculated the interactions based on these scores. Of greatest importance, the interaction effect was significant, $b=-0.26, S E=0.12, p=.026$. Simple slope analyses showed that managers' willingness to apologize was positively related to supervisors' interpersonal fairness among supervisors with a lower sense of power ( $1 S D$ below the mean; $b=0.41, S E=0.18, p=.025$ ). In contrast, there was no relationship between managers' willingness to apologize and supervisors' interpersonal fairness among supervisors with a higher sense of power ( $1 S D$ above the mean; $b=0.017$, $S E=0.07, p=.797$ ). These findings lend empirical support to our speculation that supervisors' sense of power may moderate not only the influence of their managers' informational fairness but also the influence of other forms of their managers' fairness on supervisors' interpersonal fairness.

Moreover, just as we found for managers' informational fairness, there was only a positive main effect of managers' tendencies to apologize on supervisors' enactment of other forms of fairness (i.e., procedural, distributive, and informational). Supervisors' sense of power did not moderate the positive relationships between managers' tendencies to apologize and supervisors' procedural $(b=-0.18$, $S E=0.11, p=.119)$, distributive $(b=-0.11, S E=0.12, p=.349)$, and informational fairness $(b=-0.09, S E=0.11, p=.375)$.

The results of Study 1 were consistent with the notion that supervisors' sense of power moderates the relationship between managers' informational fairness and supervisors' interpersonal fairness in a linear fashion. However, this does not necessarily preclude the possibility that the moderating influence of sense of power may take a nonlinear form. For instance, it could be that those relatively low and medium in sense of power both showed a stronger trickle-down effect that did not differ from one another, with both differing from a weaker trickle-down effect shown by those higher in sense of power. Another possibility is that those low in sense of power showed a stronger trickle-down effect than those with a medium or high sense of power, with the magnitude of the trickledown effect for the latter two groups not differing from one another.

To evaluate these and other possible nonlinear moderating effects of sense of power, we conducted separate regression analyses in which we examined the interaction between managers' informational fairness and (a) the squared term of supervisors' sense of power and (b) the cubed term of supervisors' sense of power. In fact, the interaction effect involving the squared term and the interaction effect involving the cubed term of supervisors' sense of power were 


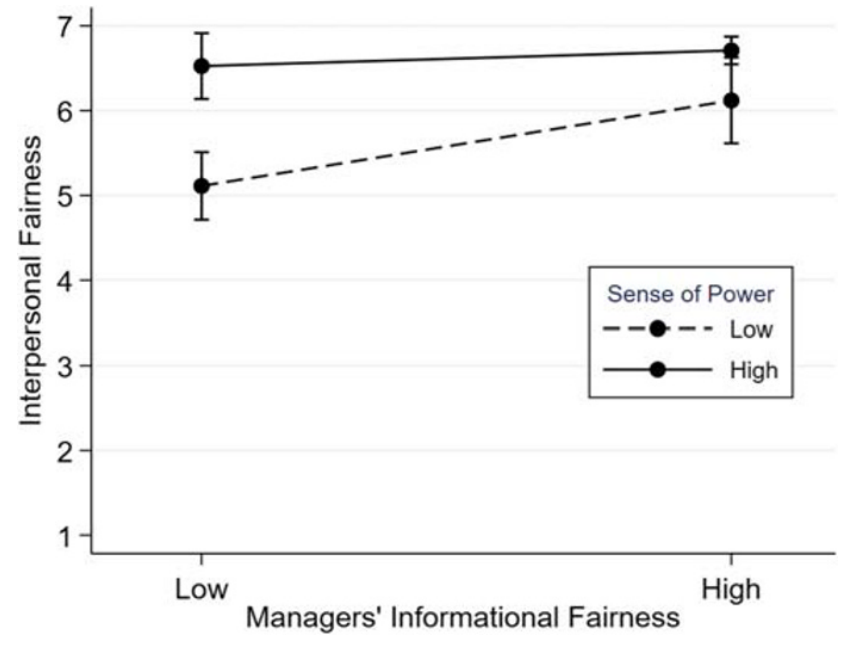

FIGURE 1 Study 1: Interaction between managers' informational fairness and Supervisors' sense of power on supervisors' interpersonal fairness [Colour figure can be viewed at wileyonlinelibrary.com]

not significant, $b=0.09, \mathrm{SE}=0.28, p=.748$ and $b=0.48, \mathrm{SE}=0.48$, $p=.312$, respectively.

The presence of these nonlinear moderating effects of sense of power either (a) reduced the significance of the focal interaction between managers' informational fairness and supervisors' sense of power to some degree (the focal interaction became marginally significant, $p=.078$ ) when the interaction between managers' informational fairness and the squared term of supervisors' sense of power was included in the regression analysis or (b) had no effect on the focal interaction (the focal interaction remained significant, $p=.018$ ) when we controlled for the interaction between managers informational fairness and the cubed term of supervisors' sense of power. Taken together, the results of these tests for nonlinearity lead us to conclude, albeit tentatively, that supervisors' sense of power moderated the relationship between managers' informational fairness and supervisors' interpersonal fairness primarily in a linear manner.

One source of ambiguity in Study 1 emanates from the fact that we used two different measures of informational fairness. Supervisors rated the extent to which their managers' explanations captured the relevant attributes of sincerity, adequacy, and legitimacy (Bobocel \& Zdaniuk, 2005), whereas the subordinates of supervisors completed the Colquitt (2001) scale, which assessed their perceptions of the quality of their supervisors' explanations (e.g., thoroughness) and their communications more broadly (e.g., timeliness). The fact that two different measures were used suggests that the significant relationship between them (i.e., the trickle-down main effect of managers' informational fairness on supervisors' informational fairness) reflects the underlying construct rather than the way in which it was operationalized. It is also possible that the trickle-down main effect would have been even stronger had we used the same measure of informational fairness.

\section{3 | STUDY 2}

Study 1 lent support to the hypothesis that the trickle-down effect of managers' informational fairness on supervisors' interpersonal fairness was more likely to emerge among supervisors with a lower sense of power. Although Study 1 used a setting that provides data of high ecological validity, its cross-sectional design does not allow us to draw causal inferences. Therefore, an important purpose of Study 2 was to test for the interactive relationship between managers' informational fairness and supervisors' sense of power using an experimental design. In Study 2, we introduced participants to the context of a simulated company and placed them in a supervisory position, in which they had a boss above them as well as direct reports below them. We manipulated the participants' sense of power and their manager's informational fairness. Given that the findings of Study 1 showed that the predicted interaction effect only emerged on the measure of interpersonal fairness enactment, the dependent variable of Study 2 consisted of participants' motivation to enact interpersonal fairness towards their subordinates.

\section{1 | Methods}

\subsubsection{Sample and procedure}

We recruited 319 employed adult participants from the United States using Amazon's Mechanical Turk (AMT). AMT is an online platform that allows researchers to collect reliable data (Buhrmester, Kwang, \& Gosling, 2011; Kilduff, Galinsky, Gallo, \& Reade, 2016). On the basis of the criteria explained below, we excluded 52 participants from our analyses. This resulted in a final sample of 267 working adults. They were $50.60 \%$ male, 37.06 years old on average $(S D=10.69)$, worked $42.05 \mathrm{~h}$ a week on average $(S D=7.30)$, and had on average 16.83 years of work experience $(S D=10.23)$. We assigned the participants randomly to one of four conditions in a 2 (Sense of Power: high vs. low) $\times 2$ (Managerial Informational Fairness: high vs. low) between-subjects design.

All manipulations and measures pertaining to the main purpose of the study are described below. We invited the AMT panelists to take part in an online study. Once they logged in to the study website, they were led to believe that they would be participating in a group task together with four other participants. We employed the well-validated in-basket task approach because this type of managerial role-playing exercise provides realism and external validity in studying organizational behavior while maintaining the advantages of doing research in a relatively controlled environment (Treviño, 1992; Zedeck, 1986). Specifically, on the basis of a methodology used previously, we told participants that they would be working in a simulated company that was hierarchically structured in three organizational layers; a visual illustration of the hierarchy was provided on a computer screen placed in front of them (De Cremer et al., 2018; van Dijke et al., 2018). Instructions indicated that one group member would be placed at the top management position, two members in the middle 
management position, and two other members in the employee position. Subsequently, we indicated that a network connection would be established between them and the other team members.

All participants were assigned on a seemingly random basis to the middle management level position. They were then informed that their boss would contact them soon with further instructions regarding the tasks they would have to complete. While waiting for the instructions of the boss to arrive, we asked them if they could help with a supposedly unrelated task in which they were given 5 min to describe a situation in which they had high (vs. low) power over other individuals. This task served as the manipulation of sense of power, which was taken from Galinsky, Gruenfeld, and Magee (2003). The participants in the high-sense-of-power condition read:

Please recall a particular incident in which you had power over another individual or individuals. By power, we mean a situation in which you controlled the ability of another person or persons to get something they wanted, or were in a position to evaluate those individuals. Please describe this situation in which you had power-what happened, how you felt, etc.

The participants in the low-sense-of-power condition read:

Please recall a particular incident in which someone else had power over you. By power, we mean a situation in which someone had control over your ability to get something you wanted, or was in a position to evaluate you. Please describe this situation in which you did not have power-what happened, how you felt, etc.

Two independent coders rated the sense of power that the participants conveyed in the recalled episodes using a 5-point Likert scale ( $1=$ not at all to $5=$ very much). Inter-rater agreement between the two coders was high, $r=.81, p<.001$; hence, we used the average ratings of the two coders as a manipulation check on sense of power.

Next, participants received an email with instructions from their manager at the top level. In reality, this information was preprogrammed and constituted the manipulation of managerial informational fairness. We operationalized this manipulation by including information about the adequacy, legitimacy, and sincerity of the explanation (see Bobocel \& Zdaniuk, 2005). Thus, the explanation delivered to the participants varied along these three dimensions to produce a high informational fairness condition and a low informational fairness condition. In the high informational fairness condition, participants received the following message:

To make you feel comfortable, I want to provide sufficient and adequate task information. Your scores will be compared, in the best and most accurate way possible, with those of the others. High scores can bring an extra financial bonus. The order of the tasks will be that we first start with business problems at the local level, then at the continental level, and finally at the global level. Why? Well, I believe that addressing first those business problems that are more familiar will build a framework that will allow you to do your tasks more efficiently. Also, be assured that you can ask questions at any point. I realize that these types of tasks can be very stressful because of their competitive nature.

In the low informational fairness condition $(n=139)$, participants received this message:

Without explaining this procedure in any detail, you should only know that I will compare your performance with the performance of the other employees. You may have a chance to win an extra financial bonus. I have decided that the order of the tasks will be that you first start with business problems at the local level, then at the continental level, and finally at the global level. I am sure no explanation is needed to understand why this is the case. Also, do not ask me too many questions.

As a check on the informational fairness manipulation, participants rated the extent to which they agreed with three questions ( 1 = strongly disagree, 7 = strongly agree), for example, "My supervisor has given me sufficient and adequate explanation about what I need to do," "The explanation provided by my supervisor was appropriate and acceptable," and "My supervisor comes across as sincere and caring in how he explains things" (Cronbach's $\alpha=.93$ ).

We then measured the dependent measure: interpersonal fairness. Participants read that shortly, they would be asked to contact one of their employees. They were then asked to indicate how they will approach the employee. We used Colquitt's (2001) 4-item interpersonal fairness scale used in Study 1 ( 1 = not at all, 7 = very much); for example, "How much effort will you put in making sure that you treat your employee with respect" (Cronbach's $\alpha=.95$ ).

After completing the interpersonal fairness measure, participants were told that the experiment was over due to an error in the established connection between the organizational members. Participants read that they were going to be redirected to the end of the study in which we introduced attention checks and measured demographics. At the end of the experiment, participants were given an open-ended opportunity to write any remarks they might have.

\subsection{2 | Participant exclusion}

We asked participants to indicate their position in the organizational hierarchy in the experiment (top management, middle management, or employee). We removed 12 participants who did not correctly indicate their assigned position. At the end of the experiment, we 
included an additional attention check, in which participants were required to choose the fifth response option to the question, "Who is your favorite classical music composer?" (Oppenheimer, Meyvis, \& Davidenko, 2009). A total of 29 participants failed this attention check and were excluded from our analyses. Finally, we removed from analyses 11 participants who failed to describe the high/low power condition requested of them. A Pearson $\chi^{2}$ test of a 4 (conditions) $\times 2$ (selected or not) cross-tabulation revealed that the percentage of excluded participants did not differ among the four experimental conditions $\left(\chi^{2}=1.73, d f=3, p=.630\right)$.

\section{2 | Results}

\subsection{1 | Manipulation checks}

A two-way analysis of variance (ANOVA) revealed that participants in the high-sense-of-power condition experienced a higher sense of power than participants in the low-sense-of-power condition $(\mathrm{Ms}=4.32$ vs. $1.54, \mathrm{SDs}=0.56$ vs. 0.68 , respectively), $F(1,263)=1,304.57, p<.001, \eta^{2}=.83$. Neither the main effect of managerial informational fairness, $F(1,263)=0.06, p=.803, \eta^{2}=.00$, nor the interaction effect was significant, $F(1,263)=0.33, p=.568$, $\eta^{2}=.00$.

Further, a two-way ANOVA on the informational fairness scale yielded only a significant main effect of informational fairness, $F(1,263)=117.59, p<.001, \eta^{2}=.31$. Explanations were rated as more adequate, acceptable, and sincere in the high informational fairness condition than in the low informational fairness condition (Ms $=5.05$ vs. $3.15, S D s=1.31$ vs. 1.53 , respectively). Neither the main effect of power, $F(1,263)=0.01, p=.910, \eta^{2}=.00$, nor the interaction effect was significant, $F(1,263)=0.34, p=.559, \eta^{2}=.00$. In sum, both experimental manipulations were successfully induced.

\subsection{2 | Hypothesis testing}

A two-way ANOVA on participants' motivation to enact interpersonal fairness showed a main effect of informational fairness, $F(1,263)=7.76, p=.006, \eta^{2}=.03$. Participants were more willing to enact interpersonal fairness in the high informational fairness condition than in the low informational fairness condition $(\mathrm{Ms}=6.44$ vs. $6.09, S D s=.86$ vs. 1.23 , respectively). The main effect of power was not significant, $F(1,263)=3.2, p=.070, \eta^{2}=.01$. Of greater importance, the interaction effect was significant, $F(1,263)=4.31$, $p=.039, \eta^{2}=.02$; see Figure 2. Simple effects showed that among participants with a lower sense of power, high informational fairness led to greater motivation to enact interpersonal fairness $(M=6.45$, $S D=0.87)$ than low informational fairness, $M=5.82, S D=1.33$; $F(1,263)=11.92, p<.001$. Among participants with a higher sense of power, high informational fairness did not lead to greater motivation to enact interpersonal fairness $(M=6.42, S D=0.86)$ compared with low informational fairness, $M=6.33, S D=1.09 ; F(1,263)=0.12$, $p=.739$.

\section{3 | Discussion}

With a more internally valid research design than that used in Study 1, Study 2 provided converging support for the previous findings. Nonetheless, Study 2 had some limitations. Although the results of Study 2 showed that the positive relationship between managers' informational fairness and supervisors' interpersonal fairness was significantly stronger among those lower than higher in sense of power, in the absence of a control group, we cannot tell if the significant difference in Study 2 between the higher and lower power conditions is due to the higher power group, to the lower power group, or to a combination of the two. It also is worth noting that the mean level of interpersonal fairness across conditions was high in Study 2 (as it was in Study 1). However, this is not uncommon, having been found in prior research (e.g., Matta, Scott, Guo, \& Matusik, 2019; Wo et al., 2015; Zapata et al., 2016). Nevertheless, it is an open question whether the interactive relationship between managers' informational fairness and supervisors' sense of power found in both studies would generalize to contexts in which the overall level of supervisors' interpersonal fairness is lower.

It also may have been the case that the manipulation of managerial informational fairness included other dimensions of fairness. For instance, part of the message in the high informational fairness condition was "be assured that you can ask questions at any point. I realize that these types of tasks can be very stressful because of their competitive nature," whereas the corresponding part of the message in the low informational fairness condition was "I am sure no explanation is needed to understand why this is the case. Also, do not ask me too many questions." This may have led participants also to experience greater interpersonal fairness in the high informational fairness versus the low informational fairness condition, a possibility that cannot be entirely discounted.

However, even if the informational manipulation introduced other elements of fairness such as interpersonal fairness, we would still expect to find a moderating effect of sense of power on the trickledown effect of managers' interpersonal fairness on supervisors' interpersonal fairness. This is because of the nature of the dependent variable: interpersonal fairness, which allows for greater personal discretion than other forms of fairness. Because interpersonal fairness allows for relatively high personal discretion, we would expect the person variable (supervisors' sense of power) to moderate the relationship between managers' interpersonal fairness and supervisors' enactment of interpersonal fairness. Indeed, the results of a subsidiary analysis in Study 1 lent support to this reasoning.

Finally, the recall prime that we used to manipulate sense of power has been criticized for possibly introducing demand characteristics, especially when it is accompanied by a manipulation check measure that is completed by participants themselves (Sturm \& Antonakis, 2015). To reduce the possible impact of demand 


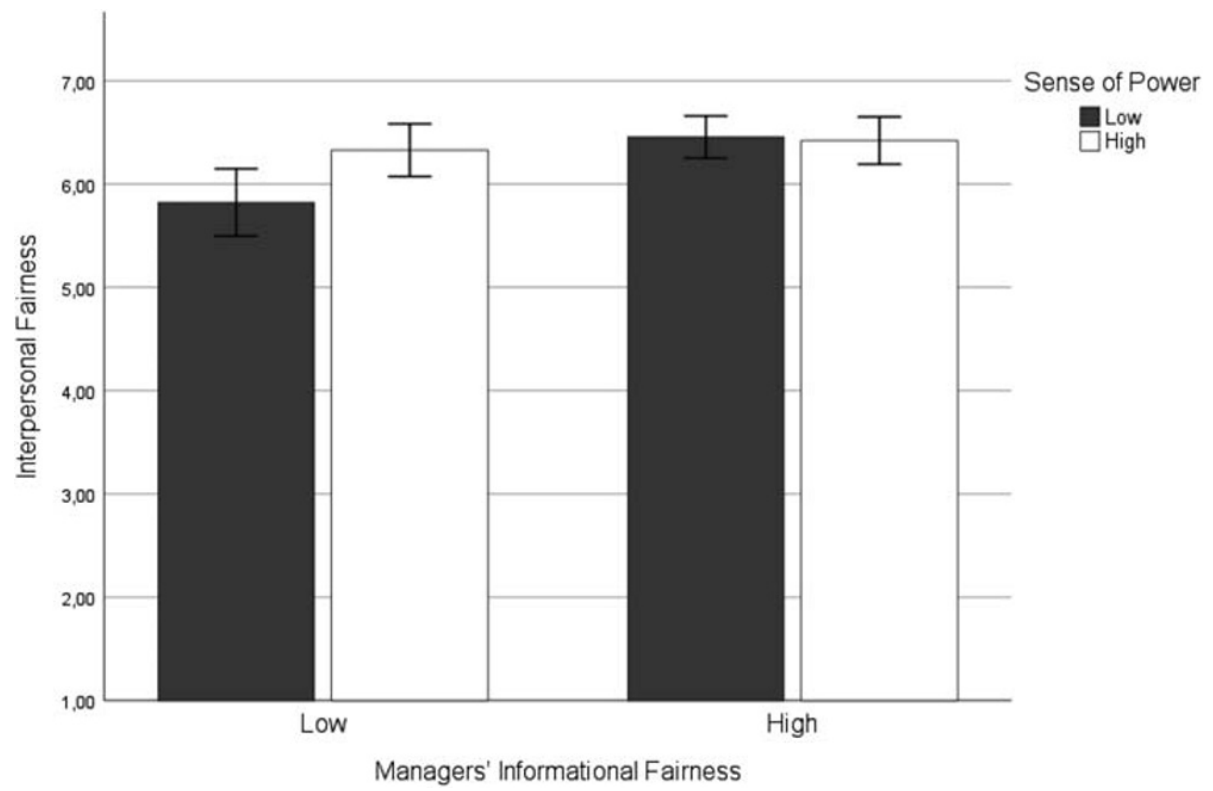

FIGURE 2 Study 2: Interaction between managers' informational fairness and supervisors' sense of power on supervisors' motivation to enact interpersonal fairness

characteristics, we presented the recall task as unrelated to the main study; it was something participants were asked to do while allegedly waiting to complete the main task. Furthermore, instead of including manipulation check items asking participants how powerful they felt, we had their recollections judged by trained raters. On a related note, Rinderknecht (2019) recently expressed concern about the viability of using a power-based recall priming manipulation when collecting data on AMT as we did in Study 2. Rinderknecht found that the priming manipulation of power employed in Study 2 may be less effective than other manipulations of power in the AMT context, such as assigning participants to play roles varying in degree of power (e.g., boss vs. subordinate). This suggests that, if anything, the moderating effect of supervisors' sense of power might have been even stronger in Study 2 if we had we used the alternative way of manipulating sense of power employed by Rinderknecht.

\section{4 | GENERAL DISCUSSION}

The present findings make multiple contributions to the "fifth wave" of justice research, which includes delineating when and why supervisors behave more versus less fairly to their direct reports (e.g., Brockner et al., 2015; Scott et al., 2009). In particular, we join recent work in the area of justice trickle-down effects (e.g., Wo et al., 2015), extending this literature empirically and conceptually. Empirically, we delineate when justice trickle-down effects are more versus less likely to occur. The results of both studies showed that supervisors with a lower sense of felt power were more likely to treat their direct reports in a manner consistent with how they were treated by their managers (i.e., managers' informational fairness trickled down to influence supervisors' interpersonal fairness), relative to supervisors who experienced a higher sense of power.
Conceptually, we help to understand when and why people may be more versus less likely to show a justice trickle-down effect. A question of fundamental importance in social and personality psychology is when are people more likely to guide their behavior on the basis of internal versus external sources of information (i.e., the person-situation debate). One determinant of the influence on behavior of internal versus external cues is the strength of the situation (Judge \& Zapata, 2015; Mischel, 1973). Strong situations influence people's behavior without allowing person variables to have much of an effect. In contrast, weak situations, such as those that give people discretion in how to behave, allow for the influence of theoretically relevant person variables, in this instance, their sense of power.

Grounding the present findings in Mischel's (1973) notion of situational strength may help to delineate when and why other variables residing within persons may influence the magnitude of justice trickledown effects. One element of situational strength is the extent to which it gives people discretion in how to respond, which is more the case for interpersonal fairness than for the other dimensions of fairness (Scott et al., 2009). However, other inputs into situational strength may dictate when justice trickle-down effects are likely to be influenced by person variables residing within supervisors. For example, imagine two supervisors ( $A$ and $B$ ), each of whom reports to two different bosses, a common occurrence in matrix organizations. In Supervisor A's case, both bosses exhibit the same level of informational fairness (their boss' behavior is consistent with each other, which sends a clear message to Supervisor $A$ as to how s/he should behave). In Supervisor B's case, the bosses are inconsistent: One exhibits high informational fairness, whereas the other exhibits low informational fairness. Given that the situation faced by Supervisor B is weak (relative to the one faced by Supervisor A), it may be expected that person variables residing within Supervisor B are more likely to influence how fairly she behaves towards her direct reports than 
would be the case for Supervisor A. For instance, Supervisor B's level of moral identity (a known predictor of people's tendencies to behave fairly; Brebels et al., 2011) may be more positively related to her tendency to behave fairly towards her direct reports than would be the case for Supervisor A.

The present studies also contribute to theory and research on how the various forms of managerial fairness meaningfully differ from one another. Scott et al. (2009) suggested and research has shown (Scott et al., 2014) that interpersonal fairness allows managers to exert greater discretion in its enactment relative to other forms of managerial fairness (distributive, procedural, and informational), which are more organizationally controlled. The present research demonstrated a noteworthy consequence of the difference in discretion associated with the various forms of fairness: A person variable (supervisors' sense of power) was more likely to moderate a justice trickle-down effect that allowed for greater discretion (supervisors' expression of interpersonal fairness).

Furthermore, this is one of the few studies to show that managers' sense of power may be linked to their enactment of interpersonal fairness (see also Blader \& Chen, 2012, study 3). At first blush, the present findings seem inconsistent with those of Blader and Chen who found that sense of power caused people to behave with lower fairness. (Blader and Chen also found that the sense of high status led to the enactment of higher levels of fairness.) We found that those with a higher sense of power either showed higher levels of interpersonal fairness (in Study 1) or equal levels of interpersonal fairness (in Study 2), relative to their counterparts who experienced less power.

There are some noteworthy differences between the present studies and those of Blader and Chen (2012), however, which may help to reconcile the seemingly disparate effects of sense of power. In their studies 1-3, Blader and Chen induced participants to experience either high power or high status, relative to a control condition. However, no other factors were varied. Thus, the potential for lower power people to vary their behavior as a function of external cues was not present in the context of Blader and Chen's studies 1-3.

In contrast, studies 4 and 5 in Blader and Chen (2012) were conducted in a way that allowed the greater sensitivity of lower power people to external cues to emerge. More specifically, in these two studies, the authors orthogonally manipulated power and status. In their studies 1-3, those led to experience high status behaved with higher levels of fairness. In their studies 4 and 5 , the positive relationship between felt status and enacted fairness was moderated by power, in which the tendency for higher status to lead to greater fairness was stronger among those who experienced lower power. At a higher level of abstraction, then, the present results are consistent with the findings of Blader and Chen in the following sense: When felt power is varied along with other factors known to influence the enactment of fairness (informational fairness from higher level management in the present studies and status in studies 4 and 5 in Blader and Chen), the fairness behavior of those lower in power is more likely to be influenced by those other cues.

\section{1 | Limitations}

The present studies are limited in several respects. For instance, neither study measured supervisors' actual enactment of interpersonal fairness. The dependent variable in Study 1 consisted of subordinates' perceptions of their supervisors' interpersonal fairness, whereas in Study 2, the dependent measure assessed behavioral intentions rather than behavior.

The present studies also did not fully specify the mechanism through which lower power people showed more of the trickle-down effect observed in the present studies. The results on the manipulation check of informational fairness in Study 2 showed that those higher and lower in power perceived the manipulation to an equivalent degree. Given that higher and lower power participants perceived the informational fairness manipulation to the same degree, it must have been that higher and lower power individuals responded differently to their (equivalent) fairness perceptions. The basis of such differing reactions, however, was not revealed by the present studies. For example, one possibility is that those higher in power were more confident than their counterparts lower in power about their own beliefs about how to respond, thereby making the higher sense of power supervisors less likely to take their cues from their managers' fairness behavior.

Finally, although a central premise of the present studies is that interpersonal fairness allows for more personal discretion than other dimensions of fairness, we did not directly evaluate the likelihood that those with more of a sense of power also experienced greater discretion than their counterparts with less of a sense of power. This possibility is implicit in our reasoning that supervisors with more of a sense of power are less likely to guide their behavior on the basis of external cues (such as their managers' fairness) and are instead more likely to act on the basis of factors internal to themselves such as their traits, values, and preferences. Although the present studies showed that those with more of a sense of power were less influenced by their managers' fairness, they do not show what did influence them.

One possibility is that other factors residing within persons that influence supervisors' expression of fairness would have more of an effect on the interpersonal fairness shown by supervisors with more of a sense of power. For instance, Brebels et al. (2011) found that those higher in moral identity adhered more to principles of procedural fairness. Let us assume that moral identity also is positively related to the expression of interpersonal fairness. If so, it may be that the positive relationship between supervisors' moral identity and their interpersonal fairness behavior will be stronger among those with more of a sense of power, who are more apt to guide their behavior on the basis of factors residing within themselves.

This speculation is consistent with a guiding principle of the present studies, namely, that greater discretion makes person variables more predictive of behavior. The source of the discretion may reside in the situation (i.e., interpersonal fairness allows for greater discretion than do the other forms of fairness), and it also may reside in the person (those with more of a sense of power experience greater discretion than do those with less of a sense of power). However, given that 
the design of the present studies did not include other theoretically relevant person variables (besides sense of power), we were unable to evaluate whether such factors would have more of an influence on the interpersonal fairness shown by those with more of a sense of power. This speculation does, however, provide an opportunity for future research.

\section{2 | Practical implications}

Numerous studies have shown that the interpersonal fairness with which employees are treated by their supervisors affects a wide array of work attitudes and behaviors (e.g., Margolis \& Molinsky, 2008; Molinsky \& Margolis, 2005; Skarlicki \& Folger, 1997; Skarlicki, Folger, \& Gee, 2004). Hence, the present studies provide insight into the practically important questions of when and why supervisors exhibit interpersonal fairness towards their subordinates. The main effect of informational fairness received from higher levels of management found in both studies is yet another reminder that the extent to which supervisors "on the ground" behave with high interpersonal fairness starts at the top. In fact, the present findings illustrate a crossover main effect in that managers' informational fairness influenced supervisors' enactment of interpersonal fairness.

Furthermore, the moderating effects of sense of power on the trickle-down effect of managers' informational fairness on supervisors' interpersonal fairness found in both studies (and the conceptually analogous interaction effect between managers' tendencies to apologize and supervisors' sense of power in the subsidiary analysis in Study 1) identify when those at the top need to be particularly mindful to behave with high degrees of fairness. Whenever employees are likely to be experiencing a reduced sense of power, such as during times of organizational transition or when employees have recently joined the organization, they may be particularly likely to guide their behavior on the basis of external cues. This is precisely when those at higher levels of management need to serve as positive role models by exhibiting high levels of fairness.

\section{ORCID}

Marius van Dijke (D) https://orcid.org/0000-0001-9974-5050

Brian Holtz (D) https://orcid.org/0000-0002-0666-5834

\section{REFERENCES}

Adams, J. S. (1965). Inequity in social exchange. In Advances in experimental social psychology (Vol. 2) (pp. 267-299). New York: Academic Press.

Aiken, L. S., \& West, S. G. (1991). Multiple regression: Testing and interpreting interactions. Thousand Oaks, CA: Sage Publications.

Ambrose, M. L., \& Schminke, M. (2009). Assessing roadblocks to justice: A model of fair behavior in organizations. J.J Martocchio \& H. Liao In Research in Personnel and Human Resources Management, 28, (pp. 219-263). Bingley: Emerald Group Publishing Limited.

Ambrose, M. L., Schminke, M., \& Mayer, D. M. (2013). Trickle-down effects of supervisor perceptions of interactional justice: A moderated mediation approach. Journal of Applied Psychology, 98, 678-689. https://doi.org/10.1037/a0032080
Anderson, C., \& Galinsky, A. D. (2006). Power, optimism, and risk-taking. European Journal of Social Psychology, 36, 511-536. https://doi.org/10. 1002/ejsp.324

Anderson, C., John, O. P., \& Keltner, D. (2012). The personal sense of power. Journal of Personality, 80, 313-344. https://doi.org/10.1111/j. 1467-6494.2011.00734.x

Bies, R. J. (1987). The predicament of injustice: The management of moral outrage. Research in Organizational Behavior, 9, 289-319.

Bies, R. J., Shapiro, D. L., \& Cummings, L. L. (1988). Casual accounts and managing organizational conflict: Is it enough to say it's not my fault? Communication Research, 15, 381-399. https://doi.org/10.1177/ 009365088015004003

Blader, S. L., \& Chen, Y.-R. (2012). Differentiating the effects of status and power: A justice perspective. Journal of Personality and Social Psychology, 102, 994-1014. https://doi.org/10.1037/a0026651

Bobocel, D. R., \& Zdaniuk, A. (2005). How can explanations be used to foster organizational justice? In J. Greenberg \& J. A. Colquitt (Eds.), Handbook of organizational justice (pp. 469-498). Mahwah, NJ: Lawrence Erlbaum.

Bradley, S. W., Shepherd, D. A., \& Wiklund, J. (2011). The importance of slack for new organizations facing "tough" environments. Journal of Management Studies, 48, 1071-1097. https://doi.org/10.1111/j.14676486.2009.00906.x

Brebels, L., De Cremer, D., Van Dijke, M., \& Van Hiel, A. (2011). Fairness as social responsibility: A moral self-regulation account of procedural justice enactment. British Journal of Management, 22, S47-S58. https://doi.org/10.1111/j.1467-8551.2010.00715.x

Brockner, J., Wiesenfeld, B. M., Siegel, P. A., Bobocel, D. R., \& Liu, Z. (2015). Riding the fifth wave: Organizational justice as dependent variable. Research in Organizational Behavior, 35, 103-121. https://doi. org/10.1016/j.riob.2015.07.002

Bryant, M., \& Stensaker, I. (2011). The competing roles of middle management: Negotiated order in the context of change. Journal of Change Management, 11, 353-373. https://doi.org/10.1080/14697017.2011. 586951

Buhrmester, M., Kwang, T., \& Gosling, S. D. (2011). Amazon's Mechanical Turk: A new source of inexpensive, yet high-quality, data? Perspectives on Psychological Science, 6, 3-5. https://doi.org/10.1177/ 1745691610393980

Campbell, D. T., \& Fiske, D. W. (1959). Convergent and discriminant validation by the multitrait-multimethod matrix. Psychological Bulletin, 56, 81-105. https://doi.org/10.1037/h0046016

Chen, S. A., Lee-Chai, Y., \& Bargh, J. A. (2001). Relationship orientation as a moderator of the effects of social power. Journal of Personality and Social Psychology, 80, 173-187. https://doi.org/10.1037/0022-3514. 80.2.173

Colquitt, J. A. (2001). On the dimensionality of organizational justice: A construct validation of a measure. Journal of Applied Psychology, 86, 386-400. https://doi.org/10.1037/0021-9010.86.3.386

Colquitt, J. A., Greenberg, J., \& Zapata-Phelan, C. P. (2005). What is organizational justice? A historical overview. In J. Greenberg \& J. A. Colquitt (Eds.), The handbook of organizational justice (pp. 3-56). Mahwah, NJ: Erlbaum.

DeCelles, K. A., DeRue, D. S., Margolis, J. D., \& Ceranic, T. L. (2012). Does power corrupt or enable? When and why power facilitates selfinterested behavior. Journal of Applied Psychology, 97, 681-689. https://doi.org/10.1037/a0026811

De Cremer, D., Van Dijke, M., Schminke, M., De Schutter, L., \& Stouten, J. (2018). The trickle-down effects of perceived trustworthiness on subordinate performance. Journal of Applied Psychology, 103, 1335-1357. https://doi.org/10.1037/apl0000339

Floyd, S. W., \& Wooldridge, B. (1992). Middle management involvement in strategy and its association with strategic type: A research note. Strategic Management Journal, 13, 153-167. https://doi.org/10.1002/smj. 4250131012 
Folger, R., Ganegoda, D. B., Rice, D. B., Taylor, R., \& Wo, D. X. (2013). Bounded autonomy and behavioral ethics: Deonance and reactance as competing motives. Human Relations, 66, 905-924. https://doi.org/10. 1177/0018726713482013

Galinsky, A. D., Gruenfeld, D. H., \& Magee, J. C. (2003). From power to action. Journal of Personality and Social Psychology, 85, 453-466. https://doi.org/10.1037/0022-3514.85.3.453

Galinsky, A. D., Magee, J. C., Gruenfeld, D. H., Whitson, J. A., \& Liljenquist, K. A. (2008). Power reduces the press of the situation: Implications for creativity, conformity, and dissonance. Journal of Personality and Social Psychology, 95, 1450-1466. https://doi.org/10. 1037/a0012633

Galinsky, A. D., Rucker, D. D., \& Magee, J. C. (2015). Power: Past findings, present considerations, and future directions. In M. Mikulincer \& P. R. Shaver (Eds.), APA handbook of personality and social psychology: Interpersonal relations (Vol. 3) (pp. 421-460). Washington, DC: American Psychological Association. https://doi.org/10.1037/14344-016

Greenberg, J. (1993). The social side of fairness: Interpersonal and informational classes of organizational justice. In R. Cropanzano (Ed.), Justice in the workplace: Approaching fairness in human resource management (pp. 79-103). Hillsdale, NJ: Erlbaum.

Howell, A. J., Dopko, R. L., Turowski, J. B., \& Buro, K. (2011). The disposition to apologize. Personality and Individual Differences, 51, 509-514. https://doi.org/10.1016/j.paid.2011.05.009

Judge, T. A., \& Zapata, C. P. (2015). The person-situation debate revisited: Effect of situation strength and trait activation on the validity of the Big Five personality traits in predicting job performance. Academy of Management Journal, 58, 1149-1179. https://doi.org/10.5465/amj. 2010.0837

Katz, D., \& Kahn, R. L. (1978). The social psychology of organizations (2nd ed.). New York, NY: Wiley.

Kilduff, G. J., Galinsky, A. D., Gallo, E., \& Reade, J. J. (2016). Whatever it takes to win: Rivalry increases unethical behavior. Academy of Management Journal, 59(5), 1508-1534. https://doi.org/10.5465/amj.2014. 0545

Lind, E. A., \& Tyler, T. R. (1988). The social psychology of procedural justice. New York, NY, US: Plenum Press. https://doi.org/10.1007/978-14899-2115-4

Margolis, J. D., \& Molinsky, A. (2008). Navigating the bind of necessary evils: Psychological engagement and the production of interpersonally sensitive behavior. Academy of Management Journal, 51, 847-872. https://doi.org/10.5465/amj.2008.34789639

Masterson, S. S. (2001). A trickle-down model of organizational justice: Relating employees' and customers' perceptions of and reactions to fairness. Journal of Applied Psychology, 86, 594-604. https://doi.org/ 10.1037/0021-9010.86.4.594

Matta, F. K., Scott, B. A., Guo, Z. A., \& Matusik, J. G. (2019). Exchanging one uncertainty for another: Justice variability negates the benefits of justice. The Journal of Applied Psychology, 105, 97-110.

Mawritz, M. B., Mayer, D. M., Hoobler, J. M., Wayne, S. J., \& Marinova, S. V. (2012). A trickle-down model of abusive supervision. Personnel Psychology, 6, 325-357.

Mikula, G., Petri, B., \& Tanzer, N. K. (1990). What people regard as unjust: Types and structures of everyday experiences of injustice. European Journal of Social Psychology, 20(2), 133-149. https://doi.org/10.1002/ ejsp.2420200205

Mischel, W. (1973). Toward a cognitive social learning reconceptualization of personality. Psychological Review, 80, 252-283. https://doi.org/10. 1037/h0035002

Molinsky, A., \& Margolis, J. (2005). Necessary evils and interpersonal sensitivity in organizations. Academy of Management Review, 30, 245-268. https://doi.org/10.5465/amr.2005.16387884

Oppenheimer, D. M., Meyvis, T., \& Davidenko, N. (2009). Instructional manipulation checks: Detecting satisficing to increase statistical power. Journal of Experimental Social Psychology, 45, 867-872. https:// doi.org/10.1016/j.jesp.2009.03.009

Pitesa, M., \& Thau, S. (2013). Compliant sinners, obstinate saints: How power and self-focus determine the effectiveness of social influences in ethical decision making. Academy of Management Journal, 56, 635-658. https://doi.org/10.5465/amj.2011.0891

Rinderknecht, R. G. (2019). Effects of participant displeasure on the socialpsychological study of power on Amazon's Mechanical Turk. SAGE Open, 9, 1-15.

Rousseau, D. M., \& Tijoriwala, S. A. (1999). What's a good reason to change? Motivated reasoning and social accounts in promoting organizational change. Journal of Applied Psychology, 84, 514-528. https:// doi.org/10.1037/0021-9010.84.4.514

Scott, B. A., Colquitt, J. A., \& Paddock, E. L. (2009). An actor-focused model of justice rule adherence and violation: The role of managerial motives and discretion. Journal of Applied Psychology, 94, 756-769. https://doi.org/10.1037/a0015712

Scott, B. A., Garza, A. S., Conlon, D. E., \& Kim, Y. J. (2014). Why do managers act fairly in the first place? A daily investigation of "hot" and "cold" motives and discretion. Academy of Management Journal, 57, 1571-1591. https://doi.org/10.5465/amj.2012.0644

Shi, W., Markoczy, L., \& Dess, G. G. (2009). The role of middle management in the strategy process: Group affiliation, structural holes, and tertius iungens. Journal of Management, 35, 1453-1480.

Simmons, J. P., Nelson L. D., \& Simonsohn U. (2013). Life after P-Hacking. Meeting of the Society for Personality and Social Psychology, New Orleans, LA, 17-19 January 2013. https://doi.org/10.2139/ssrn. 2205186

Skarlicki, D. P., \& Folger, R. (1997). Retaliation in the workplace: The roles of distributive, procedural, and interactional justice. Journal of Applied Psychology, 82, 434-443.

Skarlicki, D. P., Folger, R., \& Gee, J. (2004). When social accounts backfire: The exacerbating effects of a polite message or an apology on reactions to an unfair outcome. Journal of Applied Social Psychology, 34, 322-341. https://doi.org/10.1111/j.1559-1816.2004.tb02550.x

Sturm, R. E., \& Antonakis, J. (2015). Interpersonal power: A review, critique, and research agenda. Journal of Management, 41, 136-163. https://doi.org/10.1177/0149206314555769

Tepper, B. J., \& Taylor, E. C. (2003). Relationships among supervisors' and subordinates' procedural justice perceptions and organizational citizenship behaviors. Academy of Management Journal, 46, 97-105.

Thibaut, J., \& Walker, L. (1975). Procedural justice: A psychological analysis. Hillsdale, New Jersey: Lawrence Erlbaum Associates.

Treviño, L. K. (1992). Experimental approaches to studying ethical/unethical behavior in organizations. Business Ethics Quarterly, 2, 121-136. https://doi.org/10.2307/3857567

Van der Toorn, J., Tyler, T. R., \& Jost, J. T. (2011). More than fair: Outcome dependence, system justification, and the perceived legitimacy of authority figures. Journal of Experimental Social Psychology, 47, 127-138. https://doi.org/10.1016/j.jesp.2010.09.003

van Dijke, M. H., De Cremer, D., Langendijk, G., \& Anderson, C. (2018). Ranking low, feeling high: How hierarchical position and experienced power promote prosocial behavior in response to procedural justice. Journal of Applied Psychology, 103, 164-181. https://doi.org/10.1037/ apl0000260

van Gils, S., Van Quaquebeke, N., van Knippenberg, D., van Dijke, M., \& De Cremer, D. (2015). Ethical leadership and follower organizational deviance: The moderating role of follower moral attentiveness. The Leadership Quarterly, 26(2), 190-203. https://doi.org/10.1016/j. leaqua.2014.08.005

van Houwelingen, G., Van Dijke, M., \& De Cremer, D. (2017). Fairness enactment as response to higher level unfairness: The roles of selfconstrual and spatial distance. Journal of Management, 43, 319-347. https://doi.org/10.1177/0149206314530166 
Wayne, S. J., Liden, R. C., Graf, I. K., \& Ferris, G. R. (1997). The role of upward influence tactics in human resource decisions. Personnel Psychology, 50, 979-1006. https://doi.org/10.1111/j.1744-6570.1997. tb01491.x

White, H. (1980). A heteroskedasticity-consistent covariance matrix estimator and a direct test for heteroskedasticity. Econometrica, 48, 817-830. https://doi.org/10.2307/1912934

Wilcox, R. R., \& Keselman, H. J. (2004). Robust regression methods: Achieving small standard errors when there is heteroscedasticity. Understanding Statistics, 3, 349-364. https://doi.org/10.1207/ s15328031us0304_8

Wo, D. X., Ambrose, M. L., \& Schminke, M. (2015). What drives trickledown effects? A test of multiple mediation processes. Academy of Management Journal, 58, 1848-1868. https://doi.org/10.5465/amj. 2013.0670

Zapata, C. P., Carton, A. M., \& Liu, J. (2016). When justice promotes injus tice: Why minority leaders experience bias when they adhere to interpersonal justice rules. Academy of Management Journal, 59 , 1150-1173. https://doi.org/10.5465/amj.2014.0275

Zapata, C. P., Olsen, J. E., \& Martins, L. L. (2013). Social exchange from the supervisor's perspective: Employee trustworthiness as a predictor of interpersonal and informational justice. Organizational Behavior and Human Decision Processes, 121, 1-12. https://doi.org/10.1016/j. obhdp.2012.11.001

Zedeck, S. (1986). A process analysis of the assessment center method. Research in Organizational Behavior, 8, 259-296.

Zhao, G., Chen, Y. R., \& Brockner, J. (2015). What influences managers' procedural fairness towards their subordinates? The role of subordinates' trustworthiness. Journal of Experimental Social Psychology, 59 96-112. https://doi.org/10.1016/j.jesp.2015.04.002

Zheng, M. X., Yuan Y., van Dijke M., De Cremer D., \& Van Hiel A. (2020). The Interactive Effect of a Leader's Sense of Uniqueness and Sense of Belongingness on Followers' Perceptions of Leader Authenticity. Journal of Business Ethics, 164, 515-533. https://doi.org/10.1007/s10551018-4070-4

\section{AUTHOR BIOGRAPHIES}

Joel Brockner is the Phillip Hettleman Professor of Business at Columbia Business School, where he has been a faculty member for 35 years. His research interests include organizational justice, self-processes in work organizations, and decision-making.

David De Cremer is provost chair and professor in management and organisations at National University of Singapore Business School and the former KPMG-chaired professor in management studies at the University of Cambridge. He is the founder and director of the National University of Singapore Centre on Al Technology for Humankind. His research interests include leadership in the Al era, organizational justice, behavioral ethics, and trust. His latest best-selling book is Leadership by Algorithm: Who leads and who follows? (Harriman House).

Marius van Dijke is professor of behavioral ethics at Rotterdam School of Management, the Netherlands and scientific director of the Erasmus Centre of Behavioural Ethics. His research interests lie at the intersection of morality, social justice, power, trust, and leadership. He publishes in a range of leading journals in management and psychology such as Journal of Management, Organizational Behavior and Human Decision Processes, Journal of Applied Psychology, and Journal of Experimental Social Psychology.

Leander De Schutter is a PhD candidate at the Rotterdam School of Management in the Netherlands. He is interested in interpersonal processes within organizations, including topics such as justice, leadership, and trust.

Brian Holtz is a Boettner research fellow and associate professor in the Department of Human Resource Management in the Fox School of Business and Management Temple University. He received his $\mathrm{PhD}$ in industrial-organizational psychology from George Mason University. His research primarily focuses on issues of organizational trust and fairness.

Alain Van Hiel is a professor of social psychology at Ghent University, Belgium. His research focuses on the role of procedural fairness in fostering group cooperation and how fairness can prevent intercultural conflict. He has also an interest in political psychology and ideological attitudes in particular, and he studies processes involved in ethnic prejudice.

How to cite this article: Brockner J, De Cremer D, M van Dijke, De Schutter L, Holtz B, Van Hiel A. Factors affecting supervisors' enactment of interpersonal fairness: The interactive relationship between their managers' informational fairness and supervisors' sense of power. J Organ Behav. 2020; 1-14. https://doi.org/10.1002/job.2466 